\title{
FORMAS DE FEDERALISMO E DIREITOS FUNDAMENTAIS NA UNIÃO EUROPEIA
}

\author{
MÁRIO SIMÕES BARATA ${ }^{\dagger}$
}

\section{INTRODUÇÃO}

O federalismo é uma ideia política que engloba duas ou mais esferas de governo nas quais se articulam elementos de autonomia e de governo compartilhado (WATTS, 2008, p. 08). Daniel Elazar e Ronald Watts consideram que a confederação e a federação são formas de federalismo diferentes entre si. ${ }^{1}$ As confederações não reconhecem direitos fundamentais, pois não exercem autoridade direta sobre indivíduos. As federações, por seu lado, têm adoptado cartas de direitos na mira de protegerem direitos de minorias e de limitarem a ação governativa, quer a nível federal, quer sobretudo a nível infra federal. Neste artigo, procuramos estabelecer uma relação entre a proteção de direitos fundamentais numa federação e os direitos fundamentais na União Europeia, analisando em seguida o conceito de "aplicação" no Artigo 51. o (1) da Carta dos Direitos Fundamentais da União Europeia (CDFUE), tendo sobretudo em conta a legislação relacionada com a austeridade, que tem vindo a ser adoptada por alguns Estados-Membros, nomeadamente Portugal, devido à crise do euro e da dívida soberana.

\section{AS FEDERAÇÕES E OS DIREITOS HUMANOS}

A Para Ronald Watts, as federações são "essencialmente uma forma territorial de organização política", podendo ser consideradas como um mecanismo destinado a proteger diferentes grupos ou minorias (WATTS, 2008, p. 165). As federações são verdadeiramente eficazes se esses grupos e minorias estiverem concentrados em determinada região onde constituem maioria e se lograrem governar-se no quadro de uma unidade governativa regional. Watts apresenta como exemplos os cantões suíços

\footnotetext{
${ }^{+}$Doutor em Direito pela Faculdade de Direito da Universidade de Coimbra. Professor Adjunto do Instituto Politécnico de Leiria. Membro do Centro de Investigação em Estudos Jurídicos (CIEJ).

${ }^{1} \mathrm{Na}$ obra académica de Daniel Elazar (1998, p. 8), especialista norte-americano em Ciência Política, e na de Ronald Watts (2008, p. 10-11), canadiano e também ele especialista em Ciência Política, identificaram-se várias formas de federalismo, que incluem as seguintes: uniões, consociations, uniões constitucionalmente descentralizadas; federações, confederações, federacies, estados associados, condomínios, ligas, autoridades funcionais conjuntas, e híbridas.
} 
que comungam a mesma língua, a província francófona do Quebec no Canadá, e as diferentes maiorias linguísticas em vários estados da Índia.

Nem sempre ocorre as populações estarem uniformemente distribuídas nas diferentes parcelas de uma federação, sendo por isso possível encontrar em quase todas as federações minorias nas suas unidades constituintes. Daí que, na mira de solucionarem o problema da existência de importantes minorias regionais, as federações tenham adoptado ou recorrido a três tipos de soluções.

A primeira solução foi a de redefinir as fronteiras das unidades constitutivas por forma a permitir que as mesmas coincidam com a localização territorial dessas minorias (linguísticas e étnicas). Assim sucedeu na Suíça, na Índia e na Nigéria ${ }^{2}$. Contudo, esta solução pode revelar-se de difícil concretização devido à possibilidade de alguma das minorias regionais ficar abrangida pela unidade redefinida.

Uma segunda solução adoptada por algumas federações foi a de atribuir ao governo federal ou central a responsabilidade de proteger minorias intra regionais da eventual opressão por parte da maioria regional. Um exemplo dessa função de proteção encontra-se na Lei Constitucional Canadiana de 1867, que atribuía ao governo federal determinados poderes no âmbito da educação de minorias e de matérias relacionadas com os índios ${ }^{3}$. Mas também poderíamos achar outros exemplos nas Federações da Índia e da Malásia.

Uma terceira solução tem sido a de proteger minorias intra regionais mediante a consagração na constituição de um conjunto de direitos fundamentais dos cidadãos. Conquanto não fosse essa a intenção original da Bill of Rights, os Estados Unidos da América foram a primeira federação a adoptar, sob a forma de emendas constitucionais, uma lista de direitos visando limitar a ação do governo federal em 1791. No rescaldo da Guerra Civil, os Estados Unidos adoptaram a Décima Quarta Emenda à Constituição, a qual permite, mediante controlo judicial, alargar a proteção daqueles direitos contra a ação dos estados federados e do poder local ${ }^{4}$. Nesse sentido, Watts apresenta os seguintes exemplos:

2 Um exemplo da primeira solução na Suíça diz respeito à separação do Jura em relação ao cantão de Berna.

${ }^{3}$ Cf. seção 93 (4) relativa à educação de minorias, e a seção 91 (24) relativa a Índios e a territórios a eles reservados no Constitution Act, 1867 canadiano.

${ }^{4}$ A 14. ${ }^{a}$ Emenda é a mais importante da Constituição dos Estados Unidos, a seguir à Bill of Rights. Foi ratificada em 1868 e o seu objetivo principal era proteger os direitos fundamentais e as liberdades dos afro-americanos. Embora contendo cinco secções, a 
México (1917), Alemanha (1949), Índia (1950), Malásia (1963), Canadá (1982), Bélgica (1993), Rússia (1993), Brasil (1994), Nigéria (1999), e Suíça $(1999)^{5}$.

\section{DireITOS FundaMENTAIS NA UNIÃo EUROPEIA}

Estas ideias (a proteção das minorias e a adopção de uma "carta de direitos") também se encontram na Europa, em problemas relacionados com direitos fundamentais. Em primeiro lugar, os direitos das minorias são referidos como um valor no Tratado da União Europeia (TUE), estando também salvaguardados na Carta dos Direitos Fundamentais da União Europeia (Carta). Em segundo lugar, a ideia de os direitos fundamentais terem um efeito vertical, e desse modo limitarem a ação do Estado-Membro ficou também consagrada no Artigo 51. , 1, da Carta, considerada o instrumento codificador das decisões provenientes do Tribunal de Justiça da União Europeia (TJUE), em especial no caso Wachauf.

\section{Direitos das minorias}

A União Europeia (UE) tem preocupações semelhantes às das modernas federações em matéria de problemas relacionados com os direitos das minorias. O Artigo 2. do TUE, em particular, determina que

A União baseia-se nos valores do respeito pela

primeira secção da emenda é a mais importante do ponto de vista dos direitos fundamentais, porquanto determina que "todos os indivíduos nascidos nos Estados Unidos ou aí naturalizados e sujeitos à sua jurisdição são cidadãos dos Estados Unidos e do Estado no qual residem. Nenhum estado fará ou aplicará lei alguma que diminua os privilégios ou as imunidades dos cidadãos dos Estados Unidos; do mesmo modo, nenhum Estado privará a ninguém da vida, da liberdade ou da propriedade sem um processo justo; nem privará a ninguém, dentro da sua jurisdição, da igualdade de proteção perante as leis". O Supremo Tribunal dos Estados Unidos começou a aplicar a Bill of Rights, contra legislação estadual e local, no ano de 1897, na mira de proteger propriedade privada. O processo (Chicago, Burlington, \& Quincy Railroad v. Chicago) era acerca da indemnização justa e envolvia a 5. ${ }^{a}$ Emenda. Para uma tabela com a cronologia da incorporação da Bill of Rights, com informação sobre o ano, a questão e a emenda em causa, bem como a identificação do caso, cf. Stephens Jr. et al. (2012, p. 27).

${ }^{5}$ Este e outros exemplos de federações que adoptaram esta solução, pode encontrar-se em Watts (2008, p. 166). 


\section{FORMAS DE FEDERALISMO E DIREITOS FUNDAMENTAIS NA UNIÃO EUROPEIA}

dignidade humana, liberdade, democracia, igualdade, estado de direito e respeito pelos direitos de pessoas pertencentes a minorias. Estes valores são comuns aos Estados-Membros, numa sociedade caracterizada pelo pluralismo, a não discriminação, a tolerância, a justiça, a solidariedade e a igualdade entre homens e mulheres.

Respeitar os direitos humanos, que incluem os direitos de pessoas pertencentes a minorias, constitui portanto um dos valores fundamentais da União Europeia.

Além desta referência jurídica, a Carta alude às minorias no Artigo 21. ․ 1. Na disposição em causa consagram-se os seguintes pontos:

É proibida a discriminação em razão, designadamente, do sexo, raça, cor ou origem étnica ou social, características genéticas, língua, religião ou convicções, opiniões políticas ou outras, pertença a uma minoria nacional, riqueza, nascimento, deficiência, idade ou orientação sexual.

Estas referências aos direitos das minorias refletem a entrada em vigor do Tratado de Lisboa ${ }^{6}$. Por outras palavras, tendo presentes as posições anteriores expressadas pelos Estados-Membros, estas referências ao conceito de minoria constituem uma novidade no direito primário da UE. Nesse sentido escrevem Allan Rosas e Lorna Amati:

a Diretiva 2000/43 sobre discriminação em razão da origem racial ou étnica tem evidente importância para a proteção das minorias, mas, sintomaticamente, o conceito de minoria está ausente da sua formulação. Doravante, a referência à "pertença a uma minoria nacional" pode-se encontrar no artigo 21. ․ (1) da Carta dos Direitos Fundamentais e, sobretudo, no Artigo 2. ${ }^{\circ}$ do TUE, que acolhe entre os valores basilares sobre os quais se funda a União o respeito dos "direitos humanos, incluindo os direitos de pessoas pertencentes a minorias". Não há muito tempo, o termo minoria nem sequer podia ser mencionado no direito da União; agora,

${ }^{6}$ O Tratado de Lisboa entrou em vigor a 1 de Novembro de 2009. 
a tutela dos direitos de pessoas pertencentes a minorias figura no âmago dos princípios constitucionais da União (ROSAS et al., 2010, p. 159).

\section{Aplicar direitos fundamentais à ação de Estados-Membros}

$\mathrm{Na}$ área dos direitos fundamentais, a defesa das minorias não constitui a única semelhança entre a União e outras federações. Há também, nesse particular, algum paralelismo entre a UE e a maioria das federações - incluindo a federação americana - relativamente à aplicação da Carta a Estados-Membros 7 . Podemos encontrar esse efeito na jurisprudência do Tribunal de Justiça da UE (TJUE) e no Artigo 51.ำ 1, da Carta.

\subsection{Jurisprudência do TJUE}

$\mathrm{Na}$ fase inicial da União, os direitos fundamentais não serviam para controlar a legalidade da atividade nacional ou dos Estados-Membros. O Tribunal de Justiça da UE declarou-se incompetente para apreciar a compatibilidade da legislação nacional com a Convenção Europeia sobre Direitos Humanos $(\mathrm{CEDH})^{8}$, posição essa que levantou grandes dificuldades, em virtude de a maior parte da aplicação do direito da União Europeia ser realizada ou executada pelos Estados-Membros.

Esta situação conduziu a doutrina a escrever sobre o impacto da mesma na coesão e na unidade do Direito Europeu caso os EstadosMembros não estejam vinculados pelos direitos fundamentais da mesma forma que as instituições da UE estão. No passo seguinte, da autoria de Robert Schütze, encontramos um exemplo das questões que a aplicação de direitos fundamentais aos Estados-Membros envolve.

Será que os direitos fundamentais também vinculam os Estados-Membros? A questão pode parecer surpreendente. Todavia, do mesmo modo que nem todas as disposições nos Tratados Europeus se destinam à União, assim também nem todas as disposições europeias serão aplicáveis aos Estados-Membros. Tradicionalmente, com efeito, o constitucionalismo

\footnotetext{
${ }^{7}$ Notam este paralelismo em particular, na doutrina do direito da UE Schütze (2012, p . 409-446), e Vital Moreira na doutrina portuguesa.

8 Cf. TJUE, Processo C-60/84 e C-61/84, Cinéthèque v. Fédération Nationale des Cinémas Français, 1985 ECR I-2605.
} 
americano tem considerado que a Bill of Rights se dirige exclusivamente à União, pelo que não poderá vincular os estados. Até certo ponto, isto mudou com a Décima Quarta Emenda, na segunda metade do século XIX. Todavia, só com a emergência da doutrina da incorporação, no início do século $X X$, é que se considerou que a Bill of Rights é diretamente aplicável aos estados. A ordem jurídica europeia adoptou esta solução mutatis mutandis, e aceitou que os direitos humanos fundamentais possam - em certas circunstâncias - aplicar-se diretamente aos EstadosMembros (SCHÜTZE, 2012, p. 435-436).

O problema concreto de determinar até que ponto os direitos fundamentais europeus vinculam os Estados-Membros, ou qual o efeito vertical dos mesmos, foi analisado pelo Tribunal Europeu de Justiça no caso Wachauf. Hubert Wachauf foi um rendeiro alemão que exigiu o pagamento de uma indemnização pela descontinuação da produção de leite. A legislação alemã que havia aplicado o regulamento comunitário dispunha que um produtor de leite pudesse solicitar indenização caso tivesse efetivamente descontinuado a produção de leite por um período de seis meses. Contudo, a legislação fazia o pagamento da indenização depender da apresentação por escrito da aprovação por parte do senhorio. Como o senhorio não deu a necessária aprovação, Wachauf não preenchia todas as condições necessárias à obtenção da indemnização. Em consequência disso, alegou que a lei alemã lhe violara o direito à propriedade, porquanto a indemnização decorria do seu trabalho durante o período de arrendamento (CHALMERS et al., 2010, p. 252).

No tocante ao efeito vertical, a decisão do Tribunal Europeu de Justiça exprime o seguinte:

os direitos fundamentais reconhecidos pelo Tribunal não são, no entanto, absolutos, devendo ser tidos em conta consoante a função social que tiverem. Nessa linha, podem-se impor restrições ao exercício desses direitos, de modo particular no contexto da organização conjunta de um mercado, desde que essas restrições correspondam efetivamente a objetivos de interesse geral levados a cabo pela Comunidade e não constituam interferência desproporcional e intolerável relativamente ao fim em questão, atentando contra a 
própria substância desses direitos. Tendo presentes esses critérios, deve observar-se que as regras da Comunidade que na sequência do termo do arrendamento tiverem, sem indemnização, privado o inquilino dos frutos do seu trabalho e dos seus investimentos na propriedade arrendada seriam incompatíveis com as exigências de garantir os direitos fundamentais na ordem jurídica comunitária.

E porque essas exigências também incumbem aos Estados-Membros quando implementam regras comunitárias, os Estados-Membros devem, na medida do possível, aplicar essas regras em conformidade com essas exigências. (...) Os regulamentos comunitários em questão(...) deixam às autoridades nacionais competentes uma margem de apreciação suficientemente ampla para lhes permitir aplicarem essas regras em consonância com as exigências da proteção dos direitos fundamentais, seja proporcionando ao inquilino a oportunidade de reter a totalidade ou uma parte da quantidade de referência caso pretenda continuar com a produção de leite, seja indenizando-o caso ele decida abandonar definitivamente essa produção. ${ }^{9}$

Embora o Tribunal não tenha feito menção explícita do diploma adoptado na Alemanha, Chalmers, Davies e Monti admitem que o acórdão esteja redigido de forma a suscitar

a forte possibilidade de a legislação alemã ter violado os seus direitos fundamentais, na medida em que priva de indemnização os inquilinos. Também ficou patente que as autoridades alemãs tiveram a responsabilidade de não terem exercido a ponderação que lhes era possível por forma a observarem as normas comunitárias em matéria de direitos fundamentais (CHALMERS et al., 2010, p. 253).

Por conseguinte, o caso Wachauf "determinou claramente que, ao aplicarem regras no quadro do direito da UE, os Estados-Membros estão

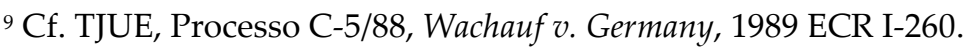


obrigados a respeitar direitos fundamentais" (JACOBS, 2010, p. 137). Trata-se de um ponto particularmente importante, uma vez que, normalmente, quem aplica regras da União são os Estados-Membros, e não tanto a União Europeia.

A proteção de direitos fundamentais europeus iria ser reforçada mais tarde pelo Tribunal de Justiça, no processo ERT, em que uma empresa de rádio e televisão (a ERT), detentora de direitos exclusivos de difusão, ao abrigo da legislação nacional grega apresentou um pedido de aplicação de medidas provisórias contra outra empresa de comunicação e contra o Município de Tessalónica, que à data operavam numa estação de televisão concorrente. Em Tribunal, as partes litigantes no processo alegaram que os direitos exclusivos conferidos à ERT violavam o seu direito a fornecer serviços. Em sua defesa, alegou o governo grego que as normas comunitárias atualmente presentes nos artigos 52.. e $61 .^{\circ}$ do Tratado sobre o Funcionamento da União Europeia (TFUE) permitiam restrições devido ao interesse público. À luz deste último argumento, sustentou a ERT que a posição do governo grego violava a liberdade de expressão grega consagrada no Artigo 10. ํ da CEDH.

Na sentença, o Tribunal declarou:

De acordo com a sua jurisprudência (...), não pode o Tribunal apreciar uma regulamentação nacional que não se situe no quadro do direito da UE face à Convenção Europeia dos Direitos do Homem. Em contrapartida, a partir do momento em que uma regulamentação deste tipo entre no campo de aplicação do direito da UE, o Tribunal de Justiça, tendo-lhe sido dirigido um pedido de decisão a título prejudicial, deve fornecer todos os elementos de interpretação necessários para a apreciação, pelo tribunal nacional, da conformidade de tal regulamentação com os direitos fundamentais cujo respeito é assegurado pelo Tribunal de Justiça, tal como resultam, em particular, da Convenção Europeia dos Direitos do Homem. Particularmente, no caso de algum Estado-Membro invocar as disposições conjugadas [dos artigos 52..$^{\circ}$ e 62..$^{\circ}$ do TFUE] para justificar uma regulamentação susceptível de entravar o exercício da livre prestação de serviços, esta justificação, prevista pelo direito da UE, deve ser interpretada à luz dos princípios gerais de direito e, nomeadamente, dos direitos fundamentais. Assim, a regulamentação 
nacional em causa só poderá beneficiar das excepções previstas nas disposições conjugadas dos artigos [52.ํ e 62. - do TFUE] se se conformar com os direitos fundamentais cujo respeito é assegurado pelo Tribunal de Justiça. ${ }^{10}$

No entender de CHALMERS et al. (2010, p. 254), esta decisão alargou significativamente $\mathrm{o}$ alcance dos direitos fundamentais na União Europeia, pelo facto de os Estados-Membros serem obrigados a observar os direitos fundamentais da União quando adoptam medidas que restringem a livre circulação de bens, serviços, capital e pessoas (i.e. quando legislam no quadro do direito europeu).

\subsection{A Carta dos Direitos Fundamentais da União Europeia}

A questão subjacente ao efeito vertical dos direitos humanos na União Europeia também se encontra na Carta dos Direitos Fundamentais da União Europeia. Nesse sentido, o Artigo 51. ํ da Carta estabelece que

As disposições da presente Carta têm por destinatários as instituições, órgãos e organismos da União, na observância do princípio da subsidiariedade, bem como os Estados-Membros, apenas quando apliquem o direito da União. Assim sendo, devem respeitar os direitos, observar os princípios e promover a sua aplicação, de acordo com as respetivas competências.

A disposição em questão regula o âmbito de aplicação da Carta. Sustenta, em primeiro lugar, que a Carta se aplica às instituições da União (nomeadamente, aquelas referidas no Artigo 13..$^{\circ}$ do TUE) e aos seus órgãos, organismos e agências, abarcando todas as autoridades estabelecidas pelos Tratados ou por legislação secundária (WARD, 2014, p. 1413). ${ }^{11}$ Em segundo lugar, fica claramente estabelecido que a Carta só vincula os Estados-Membros na medida em que apliquem direito da UE.

\section{CONTROVÉRSIAS SOBRE O ÂMBITO EXATO DO EFEITO}

${ }^{10}$ Cf. TJUE, Processo C-260/89, Elliniki Radiophonia Tiléorassi, AE and Others v. Dimotiki Etairia Pliroforissis, 1991 ECR I-2925.

${ }^{11}$ Cf., por exemplo, os Artigos 15. ${ }^{\circ}$ ou $16 .^{\circ}$ do TFUE. 
FORMAS DE FEDERALISMO E DIREITOS FUNDAMENTAIS NA UNIÃO EUROPEIA

\section{VERTICAL DECORRENTE DO ARTIGO 51., 1 DA CARTA}

Na seção anterior deste artigo, salientámos que a Carta só é aplicável aos Estados-Membros na medida em que os mesmos apliquem o direito da UE. Contudo, no tocante ao âmbito exato do seu efeito vertical, os termos da disposição têm sido objeto de alguma controvérsia no domínio da doutrina. Nesse sentido, defendem alguns autores uma interpretação mais restritiva do termo "aplicação", ao passo que outros adoptam ou defendem uma mais lata (CRAIG, 2012, p. 91-95).

Por exemplo, os autores de Wyatt and Dashwood's European Union Law (DASHWOOD et al., 2011, p. 382-383), afirmam que uma das maiores preocupações dos redatores era a de

assegurar que a Carta não viesse a ser usada para alargar as competências da UE, e que a mesma não passasse a constituir veículo através do qual o Tribunal de Justiça adquirisse jurisdição geral em matéria de direitos humanos. E por essa razão que a Carta tem aplicação mais limitada do que os princípios gerais: desse modo, ela aplica-se aos estados-Membros só na medida em que apliquem direito da UE, e não na medida em que "atuem no quadro" do direito da UE.

Piet Eeckout (2002, p. 993), por seu lado, defende uma interpretação lata da disposição, no passo que se segue: "a aplicação da Carta aos Estados-Membros na medida em que 'apliquem' direito da UE deveria alargar-se a todos os casos e contextos em que haja nexo material com o direito da EU".

Um segundo exemplo de interpretação lata do Artigo 51.o 1 da Carta é avançado por Koen Lenaerts e Piet Van Nuffel. No entender destes autores, a disposição confirma a jurisprudência do Tribunal Europeu de Justiça - nomeadamente no caso Wachauf - quando sustenta que os direitos, liberdades e princípios da Carta se aplicam aos Estados Membros na medida em que apliquem direito da UE. ${ }^{12}$ Todavia, Lenaerts e Nuffel (2011, p. 834-835) também defendem que o Artigo, 51.o , 1, será aplicável na medida em que

os Estados-Membros procedam "no quadro do direito da EU" ao aplicarem disposições do Tratado ou

${ }^{12}$ Esta posição pode-se ver na obra académica de Schütze (2012, p. 439). 
legislação da União, de modo particular quando apliquem ou executem regulamentos ou transponham diretivas para o direito interno. $\mathrm{O}$ mesmo vale para o caso em que uma medida constitua passo necessário no procedimento de adopção de uma medida comunitária e as instituições comunitárias apenas disponham de discricionariedade limitada ou nula relativamente a essa medida. Além disso, as regras nacionais são abrangidas pelo direito da UE caso obstruam o exercício de liberdades garantidas pelos Tratados.

O âmbito exato do efeito vertical decorrente do Artigo 51. ․ , 1, da Carta também é objeto da reflexão de Chalmers, Davies e Monti. Entendem esses autores que os termos da disposição refletem um entendimento mais restritivo do efeito vertical do que aquele defendido pelo Tribunal no caso ERT, porquanto a letra da lei indica que só podem ser objeto de controlo/revisão as medidas nacionais de execução. Por conseguinte, uma leitura literal da lei não cobriria medidas abrangidas pelo direito da UE. Contudo, os autores em questão notam que a ambiguidade existente na Declaração redigida pelo Secretariado 'estabelece uma relação entre esta disposição e a existente jurisprudência do Tribunal de Justiça, e indica que esta última é susceptível de integrar uma noção lata de "medida de execução" (CHALMERS et al., 2010, p. 254). ${ }^{13}$

Paul Craig (2012, p. 92-94) também reflete sobre esta discussão, defendendo uma interpretação lata da disposição. Invoca quatro razões para essa opção, sendo os seguintes os motivos subjacentes à sua posição: articular o sentido literal da disposição com o sentido que o Tribunal de

${ }_{13}$ As Explicações atinentes ao Artigo 51. ․ 1, da Carta estabelecem que "No que respeita aos Estados-Membros, resulta sem ambiguidade da jurisprudência do Tribunal de Justiça que a obrigação de respeitar os direitos fundamentais definidos no quadro da União se impõe aos Estados-Membros quando estes agem no âmbito do direito da União (acórdão de 13 de Julho de 1989, processo 5/88, Wachauf, Colect. 1989, p. 2609; acórdão de 18 de Junho de 1991, ERT, Colect. 1991, p. I-2925...)”. O Tribunal de Justiça confirmou recentemente esta jurisprudência nos seguintes termos: "Além do mais, importa lembrar que as exigências que decorrem da proteção dos direitos fundamentais na ordem jurídica comunitária vinculam também os Estados-Membros quando implementam regulamentações comunitárias..." (acórdão de 13 de Abril de 2000, processo C-292/97, Colect. 2000, p. I-2737, ponto 37). É óbvio que esta regra, tal como se encontra consagrada na presente Carta, é aplicável tanto às autoridades centrais como às instâncias regionais ou locais e aos organismos públicos quando dão execução ao direito da União. 
Justiça atribui ao termo "aplicação"; as Explicações concebidas pelo Secretariado; o argumento do equilíbrio normativo de uma interpretação lata; e a jurisprudência do Tribunal de Justiça.

Um quinto e último exemplo de interpretação lata do Artigo 51.․, 1, da Carta encontramo-lo na obra académica de José Joaquim Gomes Canotilho e Mariana Canotilho (2012, p. 39-40). Sustentam estes Autores que

no entanto, resulta da jurisprudência do TJ a imposição de uma vinculação alargada dos Estados em relação ao parâmetro comunitário de jusfundamentalidade, que deverão respeitar não só quando apliquem ou implementam normas provenientes daquele ordenamento, mas também sempre que recusem a sua aplicação ou derroguem as suas disposições normativas, com fundamento numa excepção. Este princípio aplicase, tanto às autoridades centrais quanto às autoridades regionais e locais, bem como a outras entidades públicas que apliquem direito da UE.

\section{O PROCESSO ÂKERBERG FRANSSON}

Conforme dito antes, uma leitura estrita ou literal do Artigo $51 . \stackrel{\mathrm{o}}{\text {, }}$ 1, da Carta parece restringir o cumprimento pelos Estados-Membros à aplicação estrita de direito da UE (ou seja, quando atuam como agentes), e portanto não cobre todas as situações em que legislem no quadro do direito da UE. No entanto, uma interpretação lata da disposição evitaria uma "fratura desastrada nos direitos fundamentais comunitários" entre os princípios gerais relativos a situações de derrogação e o Artigo 51 (1) da Carta sobre aplicação de direito da UE (WARD, 2014, p. 1429). A controvérsia acerca do sentido exato que na Carta tem o termo "aplicação" dissipou-se com a interpretação que fez da norma o TJUE uma interpretação na linha de acórdãos anteriores à Carta (i.e., ao Processo ERT) - no importante Processo Âkerberg Fransson, e que reafirma a posição de que os direitos fundamentais se aplicam a Estados-Membros quando legislam no quadro do direito da UE. ${ }^{14}$

14 Veja-se TJUE, Processo C-617/10, Âklagaren v. Hans Âkerberg Fransson, 2013 ECR I - 205. Para um comentário a este processo, Cf. Hancox (2015, p. 1411-1432). A relação entre o processo Âkerberg Fransson e o Artigo 51.․ (1) do CDFUE também é explorada por Ward (2014, p. 1433-1437). 
O Processo Âkerberg Fransson provém de um litígio fiscal entre um pescador e a Agência Sueca dos Impostos, sobre questões relacionadas com imposto de rendimentos e Imposto de Valor Acrescentado (IVA) declarado e pago. Na perspectiva da agência nacional sueca dos impostos havia na escritura do Sr. Fransson falhas graves em matéria de venda de ovas. Na sequência de uma estimativa baseada em critérios indiretos, a agência dos impostos decidiu agravar a declaração de rendimentos do Sr. Fransson e o IVA para 2004 e 2005, aplicando-lhe também uma penalização em sobrecargas fiscais. Após pagar as sobrecargas relativas à declaração de rendimentos insatisfatória e ao IVA, o Sr. Fransson foi processado pelo Ministério Público por graves infrações fiscais. No processo penal, a defesa considerava que o caso devia ser anulado por violar o princípio ne bis in idem, consagrado no Artigo 50. da Carta. A disposição em causa disciplina o direito a não ser julgado ou punido duas vezes em procedimentos penais pelo mesmo delito, declarando que "Ninguém pode ser julgado ou punido penalmente por um delito do qual já tenha sido absolvido ou pelo qual já tenha sido condenado na União por sentença transitada em julgado, nos termos da lei".

Devido à eventual aplicabilidade da Carta, o Tribunal Distrital Sueco recorreu ao procedimento de decisão prejudicial previsto no Artigo 267. do TFUE no sentido de obter uma decisão do TJUE que indicasse "se a política sueca de duplos processos e duplas sanções poderia ser tida como incompatível com a proibição ne bis in idem constante do Artigo 50. a da Carta" (BERNITZ, 2015, p. 157).

A decisão do TJUE no caso Âkerberg Fransson colocou um ponto final na controvérsia sobre a incerteza jurídica acerca do sentido exato do termo "aplicação" no direito da UE, Artigo 51. , 1, da Carta. O Tribunal considerou que o direito interno que impunha duplas sanções era abrangido pelo direito da UE, e por isso determinou que a Carta se aplicava. No entender de Rauchegger (2015, p. 106), esta conclusão assentava em duas razões. A primeira razão decorre da articulação das disposições consagradas na Sexta Diretiva sobre IVA com o princípio da cooperação leal que obriga os Estados-Membros "a tomarem todas as medidas legislativas e administrativas adequadas para assegurarem a arrecadação de todo o IVA devido no seu território, e para impedirem a evasão".${ }^{15}$ Em segundo lugar, o TJUE fundamentou a sua decisão também no Artigo 325. do TFUE, que impõe aos Estados-Membros a obrigação de defenderem os interesses financeiros da União Europeia. Foi por isso que o Tribunal declarou:

${ }_{15}$ Âkerberg Fransson, Opinião de AG Cruz Villalón (n 76). 


\begin{abstract}
Uma vez que os direitos fundamentais garantidos pela Carta devem, por conseguinte, ser respeitados quando uma regulamentação nacional se enquadra no âmbito de aplicação do direito da União, não podem existir situações que estejam abrangidas pelo direito da União em que os referidos direitos fundamentais não sejam aplicados. A aplicabilidade do direito da União implica a aplicabilidade dos direitos fundamentais garantidos pela Carta. ${ }^{16}$
\end{abstract}

Em suma, o TJUE rejeitou, no Processo Âkerberg Fransson, uma "interpretação estrita da jurisprudência Wachauf" (LENAERTS et al., 2014, p. 1568), e optou por um sentido mais lato para a aplicação da fórmula constante do direito da UE (FONTANELLI, 2014, p. 202). No entanto, não resolveu a esquiva questão relativa ao que especificamente "se enquadra ou não no âmbito do direito da EU”' (SILVEIRA, 2014, p. 185).

\title{
VI. ÂMBITO DO DIREITO DA EU
}

No rescaldo do Processo Âkerberg Fransson e de outros acórdãos sobre a aplicação dos direitos fundamentais à legislação doméstica de execução, Clara Rauchegger, numa tentativa de definir e delinear as fronteiras e os limites de um conceito esquivo, defende que uma medida nacional se enquadra no âmbito de aplicação do direito da UE se "a mesma cumprir uma obrigação constante do direito da UE" (RAUCHEGGER, 2015, p. 103). ${ }^{17}$ Rauchegger desenvolve esta afirmação distinguindo dois tipos de situações de execução. A primeira prende-se com a existência de uma disposição substantiva constante do direito da UE diretamente relevante, e a segunda com um mandato explícito constante do direito da UE que garante a eficácia de uma norma de direito da União. Ambas as situações desencadeiam a aplicabilidade da Carta. A primeira situação é exemplificada pelo Processo X e outros ${ }^{18}$, ao passo que o Processo Âkerberg Fransson exemplifica a segunda, relacionada com o cumprimento de uma obrigação de direito da UE. ${ }^{19}$

16 Cf. TJUE, Processo C-617/10, Âklagaren v. Hans Âkerberg Fransson, 2013 ECR I-205, parágrafo 21.

17 Para outro contributo no âmbito desta questão, Cf. Sarmiento (2015, p. 1267-1304).

${ }^{18}$ Cf. TJUE, Processos Conjuntos C-199-201/12, X and others, 2013 ECR I - 720.

19 Posição idêntica têm Koen Lenaerts et al. (2014, p. 1568), que defendem a obrigação de se cumprir direito da UE no processo Âkerberg Fransson. 
Contudo, o âmbito do direito da União não se limita ou confina ao cumprimento de uma obrigação constante do direito da UE. Os EstadosMembros também agem no quadro do direito da UE quando lhes é dada "a possibilidade de escolherem por força do direito da EU" (RAUCHEGGER, 2015, p. 107). Por outras palavras a UE dá aos EstadosMembros uma opção. Neste caso específico, Rauchegger identifica duas situações. A primeira prende-se com a possibilidade de um EstadoMembro ter a discricionariedade de optar pelo regime fornecido pelo direito secundário da União, e a segunda diz respeito a situações em que os Estados-Membros podem derrogar direito da UE. Podemos encontrar um exemplo da primeira situação no Processo N. S. e outros ${ }^{20}$, e um exemplo da segunda, que envolve a aplicação da Carta a um caso do tipo ERT, pode-se encontrar no Processo Robert Pfleger e outros ${ }^{21}$.

\section{A APLICAÇão Pós-Lisboa do ARTigo 51. DA CARTA: CORTES DE VENCIMENTO E O ÂMBITO DO DIREITO DA UE}

Os conceitos de aplicação e de âmbito do direito da UE foram abordados em vários casos relacionados com direitos fundamentais. Todavia, as decisões do Tribunal resultam controversas. O TJUE parece ter dificuldade em definir o conceito de âmbito do direito da UE e em aplicá-lo - e em consequência também a Carta - a Estados-Membros quando adoptam legislação de austeridade (i.e. direito laboral e outras reformas decorrentes de "resgates" da troika). Pode-se ver esta situação específica nos Processos Sindicato dos Bancários do Norte ${ }^{22}$, Fidelidade Mundial ${ }^{23}$ e Via Directa ${ }^{24}$.

\section{O Processo Sindicato dos Bancários do Norte}

Em Janeiro de 2012, um Tribunal do Trabalho da cidade do Porto em Portugal recorreu ao procedimento de decisão prejudicial previsto no artigo 267. . do TFUE no sentido de obter uma interpretação sobre a

${ }^{20}$ Cf. TJUE, Processos conjuntos C-411/10 e C-493/10 N. S. and others, 2011 ECR I-865.

${ }^{21}$ Cf. TJUE, Processo C-390/12, Robert Pfleger and others, 2014 ECR I-281.

${ }^{22}$ Cf. TJUE, Processo C-128/12, Sindicato dos Bancários do Norte and others v. BPN - Banco Português de Negocios SA, 2013 ECR I-149.

${ }^{23}$ Cf. TJUE, Processo C-264/12, Sindicato Nacional dos Profissionais de Seguros e Afins v. Fidelidade Mundial - Companhia de Seguros SA, 2014 ECR I-2036.

${ }^{24}$ Cf. TJUE, Processo C-665/13, Sindicato Nacional dos Profissionais de Seguros e Afins v. Via Directa - Companhia de Seguros SA, 2014 ECR I-2327. 
possibilidade de aplicação da Carta a um caso entre sindicatos representativos de funcionários bancários, nomeadamente, o Sindicato dos Bancários do Norte, e o Banco Português de Negócios (BPN), devido a cortes salariais realizados por esta instituição bancária.

As origens do caso decorrem da lei n. ${ }^{\circ}$ 55-A/2010, de 31 de Dezembro, que aprovou o Orçamento de Estado de Portugal para 2011. A lei em causa continha disposições específicas sobre cortes salariais no sector público devido à dívida soberana e à crise do euro em Portugal. O Orçamento de Estado para 2011 cortava salários superiores a 1.500 euros e impunha um corte de $10 \%$ a salários acima de 4.165 euros no setor público. $^{25}$

Estes cortes aplicavam-se a funcionários do BPN em virtude de a instituição bancária haver sido nacionalizada pelo Estado em 2008. Com este quadro em mente, o Tribunal do Trabalho suspendeu o caso e endereçou ao TJUE seis questões. Duas delas eram sobre a conformidade dos cortes salariais com o Artigo 21. da Carta, sobre a proibição da discriminação, e as outras quatro eram sobre a sua conformidade com o

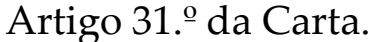

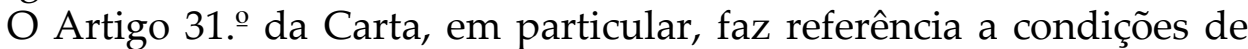
trabalho justas e adequadas, afirmando no n. 1 que 'Todos os trabalhadores têm direito a condições de trabalho saudáveis, seguras e dignas'. O Tribunal do Trabalho português (i.e. o tribunal de reenvio) pretendia saber se a disposição em questão podia ser interpretada no sentido de proibir cortes salariais sem o consentimento dos trabalhadores; se o direito em questão reconhece um direito a um salário justo; se os cortes salariais põem em causa o nível de vida dos trabalhadores e as obrigações financeiras que tenham assumido, e se são contrárias ao direito a condições de trabalho condizentes com a dignidade do trabalhador.

O TJUE decidiu não apreciar o caso por se considerar incompetente para o fazer. E baseou esta sua decisão na interpretação que fez do Artigo 51. , 1, da Carta, o qual dispõe que a Carta se aplica a Estados-Membros quando apliquem direito da UE. Para o caso em apreço, o TJUE manifestou a posição de que o Tribunal de reenvio não havia demonstrado que Portugal estava a aplicar direito da UE ao aprovar o Orçamento de Estado para 2011. Em consequência, o TJUE não respondeu

${ }^{25}$ Cf. Artigo 19. ㅇ do Orçamento de estado para 2011. O Orçamento foi aprovado pela Lei n. ${ }^{-}$55-A/2010, de 31 de dezembro de 2010, e publicado no (Diário da República, Série I, $n^{-}$253, suplemento, de 31 de Dezembro de 2010). 
às questões do Tribunal de reenvio no procedimento de decisão prejudicial. ${ }^{26}$

Contudo, esta recusa do Tribunal em atender à argumentação do presente caso é controversa, além de que não é aceitável o silêncio do Tribunal nesta matéria, porquanto a legislação portuguesa e a de outros países sobre direito laboral e sobre reformas decorrentes de um processo de resgate têm origem comunitária e incluem um elemento de direito da UE (BARNARD, 2015, p. 175).

Pode-se reconstituir esta relação ou conexão no tempo e na lei (BARNARD, 2015, p. 175-177). Em Maio de 2011, Portugal recebeu um "resgate" (i.e. um empréstimo) da troika (UE, Banco Central Europeu [BCE] e Fundo Monetário Internacional [FMI]), tendo-se comprometido a empreender uma ampla quantidade de reformas e de medidas num Memorando de Entendimento (ME). Entre essas medidas, encontra-se a reforma do seu direito laboral. Uma parte do empréstimo monetário proveio do Mecanismo Europeu de Estabilização Financeira (MEEF) adoptado ao abrigo do Regulamento 407/2010. ${ }^{27}$ Nos termos deste diploma, a decisão de conceder o empréstimo teria de incluir disposições legais sobre condicionalidade (i.e. condições de política económica geral que restabelecessem uma situação econômico-financeira sólida). Estas condições seriam definidas pela Comissão, consultando o BCE; além disso, aos Estados-Membros que requeressem empréstimo era exigido que aprovassem um programa de ajustamento. Posteriormente, o Conselho adoptou a Decisão de Aplicação 2011/344/EU, que concedia a Portugal assistência financeira e condicionava a primeira tranche do empréstimo à execução do ME. Esta decisão é particularmente importante porquanto o Artigo 3. . (5) determina que

Antes do final de 2011, e de acordo com as especificações do Memorando de Entendimento, Portugal adopta as seguintes medidas:

a) Portugal deve executar na íntegra as medidas de consolidação orçamental previstas no orçamento de 2011, no valor aproximado de 9 mil milhões de EUR, e as medidas adicionais, introduzidas antes de Maio de 2011, que ascendem a mais de 400 milhões de EUR. Estas medidas destinam-se a reduzir o déficit das

26 TJUE, Processo C-128/12, Sindicato dos Bancários do Norte and others v. BPN - Banco Português de Negocios SA, 2013 ECR I - 149, parágrafo 12. Para um comentário a este processo na doutrina portuguesa, Cf. Pinto (2013, p. 307-325).

27 O Regulamento em questão baseia-se no Artigo 122. ํ (2) do TFUE. 
administrações públicas nos prazos referidos no $n .{ }^{\circ}$ 3. As medidas do lado das receitas previstas no orçamento de 2011, no valor de 3,4 mil milhões de EUR, devem ser complementadas por um aumento das contribuições sociais através de um controlo mais rigoroso e da contribuição obrigatória por parte dos estagiários. Além das medidas do lado das despesas previstas no orçamento de 2011, devem ser aplicadas medidas suplementares, incluindo poupanças no sector da saúde, redução dos subsídios ao Setor Empresarial do Estado (SEE) e diminuição das transferências sociais. ${ }^{28}$

À luz da reconstituição anterior pode-se, portanto, dizer que a execução do déficit do Estado para 2011 foi uma questão não apenas do direito português mas também de aplicar e/ou assegurar a eficácia do direito da UE. Por outras palavras, a Decisão de Aplicação do Conselho colocava Portugal numa situação em que tinha o dever de cumprir uma obrigação constante do direito da UE. Em consequência, o Orçamento do Estado português para 2011 enquadra-se no âmbito de aplicação do direito da UE.

\section{O Processo Fidelidade Mundial}

O Tribunal manteve a sua posição num processo posterior que envolvia medidas semelhantes em Portugal. No Processo C-264/2012, sobre o Orçamento de Estado para 2012, um Tribunal do Trabalho português remeteu para o TJUE um conjunto de questões sobre a suspensão excepcional do pagamento dos vencimentos do décimo terceiro e décimo quarto mês (i.e. subsídio de férias e de Natal), durante três anos, a trabalhadores que ganhassem mais de 1100 euros mensais. ${ }^{29}$

28 2011/344/EU: Decisão de Execução do Conselho de 30 de Maio de 2011 relativa à concessão de assistência financeira da União a Portugal.

${ }^{29}$ O Artigo 21. o (1) da Lei do Orçamento de Estado, intitulado "Suspensão do pagamento de subsídios de férias e de Natal ou equivalentes", determina que: "durante a vigência do Programa de Assistência Económica e Financeira (PAEF), como medida excepcional de estabilidade orçamental é suspenso o pagamento de subsídios de férias e de Natal ou quaisquer prestações correspondentes aos 13..$^{\circ}$ e, ou, $14 .^{\circ}$ meses, às pessoas a que se refere o n. 9 do artigo 19.. da Lei n.. 55-A/2010, de 31 de Dezembro, 
O Tribunal português questionava a compatibilidade da suspensão do pagamento com a Carta, nomeadamente os Artigos 21., , 31. ${ }^{\circ}$ e o direito à negociação coletiva ${ }^{30}$.

Na sua decisão, o Tribunal de Justiça afirmou que Portugal não havia aplicado o direito da UE, e citou o Processo Sindicato dos Bancários do Norte. Recusava por isso a apreciar o caso, argumentando não ter manifestamente competência para o fazer. ${ }^{31}$ No entanto esta posição é criticável a partir de duas perspectivas.

A primeira diz respeito à questão da aplicação do direito da UE. Neste caso específico, pode-se dizer que Portugal estava de facto a aplicá-lo, se se considerar o ME como um ato normativo (COUTINHO, 2016, p. 105132), ou pelo menos garantindo a eficácia do direito da União Europeia, em virtude de o Artigo 3.․ (3) do Regulamento 407/2010 exigir que um programa de ajustamento seja preparado pelo estado beneficiário em troca de um empréstimo, e o Artigo 3. (5) do Regulamento determina que a Comissão e o Estado beneficiário devem acordar um ME. Entre os compromissos previstos no documento que Portugal assinou estava a redução da fatura relativa ao setor público como percentagem do PNB em 2012 e 2013. Além disso, o Artigo 3.ำ (6) da Decisão de Execução do Conselho 2011/344/UE afirma que

Ao longo de 2012, em conformidade com as especificações do «Memorando de Entendimento», Portugal adopta as seguintes medidas:

(a) (...).

(b) (...).

(c) O orçamento deve prever uma redução das despesas em 2012 de cerca de 3,5 mil milhões de EUR, pelo menos, incluindo uma vasta reorganização da administração central, eliminando duplicações e outras deficiências; a redução do número de municípios e freguesias; cortes nos setores da educação e da saúde, menos transferências para as autoridades regionais e locais, redução dos efetivos do sector público; ajustamentos nas

alterada pelas Leis n.. ${ }^{\circ}$ 48/2011, de 26 de Agosto, e 60-A/2011, de 30 de Novembro, cuja remuneração base mensal seja superior a $€ 1100^{\prime \prime}$.

30 TJUE, Processo C-264/12 Sindicato Nacional dos Profissionais de Seguros e Afins v Fidelidade Mundial - Companhia de Seguros SA, 2014 ECR I-2036, parágrafo 16.

31 TJUE, Processo C-264/12 Sindicato Nacional dos Profissionais de Seguros e Afins v Fidelidade Mundial - Companhia de Seguros SA, 2014 ECR I-2036, parágrafos 19, 20 e 22. 
pensões; reduções das despesas de capital e de outras despesas, tal como previsto no Programa.

Logo, não se pode negar a existência de nexo direto ou de relação material com o direito da UE. Pelo contrário, o nexo é mais evidente e mais exato do que no Caso Sindicato dos Bancários do Norte, na medida em que o sector público era especificamente visado. Por outras palavras, o Regulamento, o ME e a Decisão de Execução do Conselho colocavam Portugal numa situação em que o país tinha o dever claro e bem definido de cumprir uma obrigação constante do direito da UE.

Em segundo lugar, a decisão também é passível de crítica do ponto de vista dos direitos fundamentais e do direito laboral, uma vez que a questão da aplicação impedia o Tribunal de ter em conta o conceito de dignidade constante da Carta. Esse conceito é particularmente importante na medida em que é possível estabelecer uma relação entre remuneração e dignidade. Nesse sentido, "cortes em remunerações financeiras inesperados e não razoavelmente previsíveis pelos trabalhadores, violam a dignidade humana, por ser incompatível com o 'estado de direito' na vida laboral" (BOGG, 2014, p. 856). ${ }^{32}$

\section{O Processo Via Directa}

Um terceiro exemplo da dificuldade do TJUE com o conceito de “âmbito do direito da EU" podemos encontrá-lo no processo Via Directa. Neste caso específico, o Tribunal do Trabalho de Lisboa suspendeu um processo entre o Sindicato Nacional dos Profissionais de Seguros e Afins e a Via Directa - Companhia de Seguros SA (Via Directa), e requereu uma decisão prejudicial sobre a aplicação dos Artigos 20. e 21. ํ da Carta sobre

${ }^{32}$ No seu comentário ao Artigo 31. da CDFUE, Alan Bogg (2014, p. 856) observa que a dignidade é referida no Artigo 23.ำ da Declaração Universal dos Direitos Humanos. No Artigo 23. (1), a Declaração protege o direito dos indivíduos a condições de trabalho justas e favoráveis. Além disso, o Artigo 23.” (3) estabelece que o "direito a uma remuneração justa e favorável" deve "assegurar, ao trabalhador e à sua família uma existência condizente com a dignidade humana". O Autor sustenta que esta disposição “terá estado na base do desenvolvimento da 'dignidade' como fundamento em que assenta um direito à remuneração, nos termos do Artigo 31.․ (1) da carta da EU". 
reduções salariais ${ }^{33}$ e sobre a suspensão dos suplementos de Natal e de férias (i.e. o pagamento do $13 .^{\circ}$ e $14 .^{\circ}$ mês) consagrada no Orçamento de Estado português para 2012.34

Considerava o Tribunal de reenvio ser necessária uma decisão do TJUE sobre a aplicabilidade da Carta por forma a poder apreciar o processo principal. Para tanto, remeteu duas questões: (1) deve o princípio da igualdade de tratamento, do qual decorre a proibição da discriminação, ser interpretado como aplicável a funcionários públicos? (2) o fato de o Estado impor uma suspensão unilateral do pagamento daquelas prestações salariais e de apenas a aplicar a uma determinada categoria de trabalhadores - os funcionários públicos - constitui discriminação à luz da natureza da relação de emprego? ${ }^{35}$

O TJUE invocou o Artigo 53. (2) das Regras Processuais para decidir o caso, justificando-se com não ter jurisdição para apreciar a ação. $\mathrm{O}$ Tribunal remeteu para o Processo Sindicato Nacional dos Profissionais de Seguros e Afins v. Fidelidade Mundial e fez notar que as questões recebidas eram análogas às questões que haviam sido colocadas naquele processo. Além disso, o Tribunal apontou outra semelhança com o Processo Fidelidade Mundial, em virtude de o presente pedido "não conter qualquer elemento concreto que permita pensar que a Lei Orçamental de 2012 procurou aplicar direito da EU". ${ }^{36}$

Em suma, o TJUE justificou a Ordem de não apreciar o caso com a justificação de que o Orçamento de Estado português não aplicava direito da União, mas fê-lo sem verdadeiramente analisar as origens da legislação e sem verificar se havia algum elemento do direito da UE. Se tivesse adoptado outro caminho, teria chegado à conclusão oposta. Lamentavelmente, o TJUE adoptou, erradamente, uma interpretação estrita do termo aplicação, contrária à decisão que havia tomado no Processo Âkerberg Fransson.

${ }^{33}$ Em Portugal, a lei № 64-B/2011, de 31 de Dezembro de 2011, aprovou o Orçamento de Estado para 2012 (Diário da República, Serie I, №250, de 30 de Novembro de 2012). O Artigo 20. da Lei do Orçamento de 2012 determina que as reduções para funcionários do setor público, ao abrigo da Lei № 55-A/2010, de 31 de Dezembro de 2010, que aprovou o Orçamento de Estado para 2011 (Diário da República, Serie I, № 253, de 31 de Dezembro de 2010; 'a lei do Orçamento de 2011'), se vai manter em vigor.

${ }^{34}$ Cf. Artigo 21. (1) da lei do Orçamento de Estado de 2012.

35 TJUE, Processo C-665/13, Sindicato Nacional dos Profissionais de Seguros e Afins v. Via Directa - Companhia de Seguros SA, 2014 ECR I-2327, parágrafo 10.

36 TJUE, Processo C-665/13, Sindicato Nacional dos Profissionais de Seguros e Afins v. Via Directa-Companhia de Seguros SA, 2014 ECR I-2327, parágrafo 13. 


\section{UMA AVALIAÇÃO DO SILÊNCIO DO TJUE}

À luz da indiscutível origem comunitária e dos elementos do direito da UE, o Tribunal poderia ter seguido, na opinião de Bernard, o acórdão Âkerberg Fransson, quando diz:

Uma vez que os direitos fundamentais garantidos pela Carta devem, por conseguinte, ser respeitados quando uma regulamentação nacional se enquadra no âmbito de aplicação do direito da União, não podem existir situações que estejam abrangidas pelo direito da União em que os referidos direitos fundamentais não sejam aplicados. ${ }^{37}$

Portanto, o Tribunal podia ter concluído que "em virtude da relação entre o Regulamento MEEF, o ME, a decisão 2011/344/UE e a Lei do Orçamento do Estado para 2011, Portugal estava a agir no âmbito do direito da UE e por essa razão a Carta devia ser aplicada" (BARNARD, 2015, p. 177-178). Esta afirmação vale igualmente para o Orçamento do Estado português para 2012. Contudo, o TJUE não seguiu esta linha e não aproveitou a oportunidade proporcionada por estes três processos para refletir sobre o conceito de "aplicação", e em particular sobre o sentido de "âmbito do direito da União" e sobre que tipo de medidas nacionais nele se enquadram.

Também se critica o Tribunal por não ter usado as possibilidades de que dispunha nos Regulamentos de Processo do Tribunal de Justiça. O Artigo 94..$^{\circ}$ dos Regulamentos de Processo disciplina o conteúdo de um pedido de decisão prejudicial. Nos termos desta disposição, um pedido deve incluir três elementos, além do texto das questões remetidas ao Tribunal:

a exposição das razões que conduziram o órgão jurisdicional de reenvio a interrogar se sobre a interpretação ou a validade de certas disposições do direito da União, bem como a relação que esse órgão

37 TJUE, Processo C-617/10, Âklagaren v. Hans Âkerberg Fransson, 2013 ECR I-205, parágrafo 21. 
estabelece entre essas disposições e a legislação nacional aplicável ao litígio no processo principal. ${ }^{38}$

É necessário, portanto, que o órgão jurisdicional de reenvio estabeleça uma relação entre determinado ato de um Estado e o direito da UE (PINTO, 2013, p. 323). Por conseguinte, se nenhuma relação houver, o Tribunal declarar-se-á incompetente. No entanto, os Regulamentos de Processo também consagram um mecanismo que permite ao tribunal de Justiça pedir esclarecimentos junto do órgão jurisdicional de reenvio. Nos termos do Artigo 101. o dos Regulamentos de Processo

Sem prejuízo das medidas de organização do processo e das diligências de instrução previstas no presente regulamento, o Tribunal pode, ouvido o advogadogeral, pedir esclarecimentos ao órgão jurisdicional de reenvio, fixando um prazo para o efeito prescrito pelo tribunal.

Todavia, o Tribunal nunca fez uso desta disposição consagrada nos Regulamentos de Processo no sentido de pedir esclarecimentos adicionais dos dois Tribunais do Trabalho portugueses.

Além disso, o Tribunal não aproveitou o ensejo que estes casos the proporcionavam para refletir sobre o conceito de salário e se existe relação entre os vencimentos pagos por um empregador público ou privado e a questão da dignidade. Por outras palavras, o Tribunal não colheu aquela oportunidade para esclarecer os cidadãos europeus sobre o seu conceito de ordenados e vencimentos, e para esclarecer se existe alguma relação entre remuneração e condições de trabalho que respeitem

38 Os Regulamentos de Processo do Tribunal de Justiça foram publicados no OJ L 265, 29.9.2012, p. 1-42. O Artigo 94.. , sobre o conteúdo do pedido de decisão prejudicial, estabelece que: "[p]ara além do texto das questões submetidas ao Tribunal a título prejudicial, o pedido de decisão prejudicial deve conter: a) uma exposição sumária do objeto do litígio bem como dos factos pertinentes, conforme apurados pelo órgão jurisdicional de reenvio, ou, no mínimo, uma exposição dos dados factuais em que as questões assenta; b) o teor das disposições nacionais suscetíveis de se aplicar no caso concreto e, sendo caso disso, a jurisprudência nacional pertinente; c) a exposição das razões que conduziram o órgão jurisdicional de reenvio a interrogar-se sobre a interpretação ou a validade de certas disposições do direito da União, bem como o nexo que esse órgão estabelece entre essas disposições e a legislação nacional aplicável ao litígio no processo principal." 


\section{FORMAS DE FEDERALISMO E DIREITOS FUNDAMENTAIS NA UNIÃO EUROPEIA}

a dignidade dos trabalhadores. Neste sentido, o Tribunal pressupõe um conceito de salário na acepção de mera contrapartida ou devolução pelo trabalho vendido por um empregado ao empregador; mas será que o liga à satisfação das necessidades do trabalhador e da sua família, ou não passará esse conceito de mero instrumento de política económica? ${ }^{39}$

Este "voto de silêncio" é criticado pela doutrina, que acredita ser dever dos tribunais nacionais e do TJUE salvaguardar os direitos fundamentais nestes casos, mercê da relação direta ou do nexo material entre a austeridade e a reforma do direito laboral que está a ser adoptada em Estados-Membros como Portugal e a Grécia e no contexto europeu. ${ }^{40}$ Por outras palavras, os Estados-Membros estão a legislar no quadro do direito da União Europeia. Por conseguinte, o Tribunal devia responder à questão constitucional nuclear, que é a de saber

se os rigores da nova política europeia da condicionalidade têm de ser contrabalançados com os valores sociais, os objetivos, os direitos e os princípios consagrados pelo Tratado de Lisboa, em particular com as disposições dos Artigos 2.ำ e 3.. ${ }^{\circ}$ do TUE, e também com a cláusula horizontal prevista no Artigo 9.. do TFUE e com o reconhecimento de efeito jurídico pleno à (...) Carta" (GIUBBONI, 2014, p. 962-963).

Só nesse caso poderá o Tribunal garantir "um grau de controlo judicial comunitário sobre o que está a ser feito, em nome da UE, salvaguardando o respeito pela natureza discricionária e, em boa medida, também

39 Estas três conceitualizações de salário encontram-se na doutrina juslaboral portuguesa. Para Fernandes (2012, p. 380-387), o conceito de salário subjacente ao regime legal dos salários em Portugal corresponde à conceptualização que defende que o salário se liga à satisfação das necessidades do trabalhador e da sua família. $\mathrm{O}$ Autor indica as seguintes disposições do Código do Trabalho português: Artigo 273 e regulamentação relacionada, que regula um rendimento mínimo mensalmente garantido; Artigo 279. ${ }^{\circ}$, que estabelece que o salário de um trabalhador não pode ser totalmente direcionado para pagamento de crédito ao empregador; Artigo 333. ${ }^{\circ}$ que privilegia créditos salariais; e os Artigos 323.--327-o e 336.ำ que regulam o pagamento pronto dos salários. Estas disposições refletem uma conceptualização do salário relacionada com as necessidades do trabalhador e da sua família.

40 Em relação à legislação grega sobre austeridade abrangida pelo direito da UE, Cf. Poulou (2014, p. 1145-1176). 
política, das escolhas políticas que vão sendo feitas" (BARNARD, 2015, p. 174).

\section{CONCLUSÃO}

O federalismo é uma ideia política que articula o governo partilhado com a autonomia, e abarca várias formas. Uma confederação e uma federação não são senão duas formas de federalismo que tratam de formas diversas os direitos fundamentais. As federações recorreram aos direitos fundamentais para protegerem as minorias e os cidadãos da ação governamental, quer ao nível federal quer ao nível das unidades constituintes. Estas ideias também se encontram na Europa. A União Europeia tem acautelado a proteção dos direitos das minorias e considera-os um valor da União. Além disso, os direitos fundamentais aplicam-se aos Estados-Membros sempre que os mesmos aplicam o direito da UE e legislam no quadro desse mesmo direito. Prova disso mesmo encontra-se na jurisprudência do TJUE quer anterior ao Tratado de Lisboa quer posterior à entrada em vigor do Artigo 51.․․ 1, da Carta. Todavia, a mesma aplicação da Carta aos Estados-Membros quando legislam no quadro do direito da UE não deixou de suscitar controvérsia.

Essa controvérsia aflora nos Processos Sindicato dos Bancários do Norte, Fidelidade Mundial, e Via Directa, em relação aos quais o TJUE concluiu não ter competência para os apreciar, com o argumento de que Portugal não havia aplicado nenhum direito da UE. Por seu lado, a doutrina encontra significativas relações com o direito da União Europeia na legislação adoptada em contexto da crise do euro e das dívidas soberanas, e não deixou de criticar o Tribunal por não haver detectado essa relação. Além disso, censura o Tribunal por não controlar o que se vem fazendo em nome da UE em países como Portugal e a Grécia (i.e. reformas do direito laboral, e outras, em troca de resgates financeiros).

Finalmente, o futuro da proteção dos direitos fundamentais e a possibilidade de construir uma Europa mais federal (i.e. uma Federação Europeia) dependerá de uma interpretação lata do Artigo 51. ․ 1, da Carta e, nesse sentido, de uma sua aplicação a legislação adicional dos EstadosMembros, ou dependerá da revisão integral da disposição que abrangeria toda a legislação dos Estados-Membros e que, em consequência, tornaria o efeito vertical idêntico àquele que existe nas federações modernas. 


\section{REFERÊNCIAS}

BARNARD, Catherine. The Silence of the Charter: Social Rights and the Court of Justice. In: SYBE, Vries et al. (eds.). The EU Charter of Fundamental Rights as a Binding Instrument: Five Years Old and Growing. Oxford: Hart Publishing, 2015, p. 173-188.

BERNITZ, Ulf. The Scope of the Charter and its Impact on the Application of the ECHR: The Âkenberg Fransson Case on Ne Bis in Idem in Perspective. In: SYBE, Vries et al. (eds.). The EU Charter of Fundamental Rights as a Binding Instrument: Five Years Old and Growing. Oxford: Hart Publishing, 2015, p. 155-172.

BOGG, Allan. Article 31: Fair and Just Working Conditions. In: PEERS, Steve et al. (eds.). The EU Charter of Fundamental Rights: A Commentary. Oxford, Hart Publishing, 2014, p. 833-867.

CANOTILHO, José J. G.; CANOTILHO, Mariana. Tue Art. 6o․ In: LOPES Porto; MANUEL-ANASTÁCIO, Gonçalo (coords.). Tratado de Lisboa: Anotado e Comentado. Coimbra: Almedina, 2012, p. 39-42.

CHALMERS, Damian et al.. European Union Law. 2ed. Cambridge: Cambridge University Press, 2010.

COUTINHO, Francisco Pereira. Austerity on the loose. In: Portugal: European judicial restraint in times of crisis. Perspectives on Federalism, v. 8, n. 3, p. E-105-E-132, 2016.

CRAIG, Paul. The Charter, the ECJ and national courts. In: ASHIAGBOT, Diamond et al. (eds.). The European Union After the Treaty of Lisbon. Cambridge: Cambridge University Press, 2012, p. 78-108.

DASHWOOD, Alan et al. Wyatt and Dashwood's European Union Law. Bloomsbury Publishing, 2011.

EECKHOUT, P. The EU Charter of Fundamental Rights and the Federal Question. CML Rev, v. 39, 2002, p. 945-994. 
ELAZAR, Daniel Judah. Constitutionalizing globalization: the postmodern revival of confederal arrangements. Rowman \& Littlefield, 1998.

FERNANDES, António Monteiro. Direito do Trabalho. 16 ed. Leya, 2014.

FONTANELLI, Filippo. The Implementation of European Union Law by Member States Under Article 51 (1) of the Charter of Fundamental Rights. Colum. J. Eur. L., v. 20, p. 193, 2013.

HANCOX, Emily. Meaning of Implementing EU Law under Article 51 (1) of the Charter: Akerberg Fransson. Common Market L. Rev., v. 50, p. 1411, 2013.

GUIBBONI, Stefano. European citizenship and social rights in times of crisis. German LJ, v. 15, p. 935, 2014.

JACOBS, F. G. Wachauf and the protection of fundamental rights in EC law. In: The Past and Future of EU Law: The Classics of EU Law Revisited on the 50th Anniversary of the Rome Treaty. Oxford: Hart Publishing, 2010, p. 133-139.

LENAERTS, Koen; GUTIÉRREZ-FONS, José Antonio. The place of the charter in the EU constitutional edifice. In: The EU Charter of Fundamental Rights. Nomos Verlagsgesellschaft mbH \& Co. KG, 2014. p. 1600-1637.

LENAERTS, Koenraad; NUFFEL, Piet Van. European Union Law. London: Sweet \& Maxwell, 2011.

MOREIRA, Vital. Carta dos Direitos Fundamentais da União Europeia. In: ANASTÁCIO, G., \& PORTO, M. L. Tratado de Lisboa: anotado e comentado. Coimbra, Almedina, 2012, p. 1383-1408.

PINTO, Ana I. Soares. A Carta dos Direitos Fundamentais da União Europeia e a Redução Salarial dos Funcionários Públicos: Anotação ao Despacho do Tribunal de Justiça de 7 de Março de 2013, Sindicato dos Bancários do Norte e Outros, Processo C-128/12. Revista do Centro de Estudos Judiciários, v. 1, 2013, p. 307-325. 
POULOU, Anastasia. Austerity and European Social Rights: How Can Courts Protect Europe's Lost Generation. German LJ, v. 15, p. 1145, 2014.

RAUCHEGGER, Clara. 2015, The Interplay Between the Charter and National Constitutions after Âkerberg Fransson and Melloni: Has the CJEU Embraced the Challenges of Multilevel Fundamental Rights Protection? In: VRIES, Sybe et al. (eds.). The EU Charter of Fundamental Rights as a Binding Instrument: Five Years Old and Growing. Oxford: Hart Publishing, 2015, p. 93-131.

ROSAS, Allan; ARMATI, Lorna. EU constitutional law: an introduction. Oxford: Hart Publishing, 2010.

SARMIENTO, Daniel. Who's Afraid of the Charter; The Court of Justice, National Courts and the New Framework of Fundamental Rights Protection in Europe. Common Market L. Rev., v. 50, p. 1267, 2013.

SILVEIRA, Alessandra. Do Âmbito de Aplicação da Carta dos Direitos Fundamentais da União Europeia: Recai ou não Recai - Eis a Questão! Julgar, v. 22, 2014, p. 179-209.

STEPHENS JR., Otis H.; SCHEB, John M. American Constitutional Law 2: Civil Rights and Liberties. Boston: Wadsworth, 2012.

WARD, Angela. Article 51 - Field of Application. In: PEERS, Steve et al. (eds.). The EU Charter of Fundamental Rights: A Commentary. Oxford: Hart Publishing, 2014, p. 1413-1454.

WATTS, Ronald L.. Comparing Federal Systems. 3 ed. Montreal: McGillQueen's University Press, 2008.

FORMAS DE FEDERALISMO E DIREITOS FUNDAMENTAIS NA UNIÃO EUROPEIA

FORMS OF FEDERALISM AND FUNDAMENTAL RIGHTS IN THE EUROPEAN

UNION 